\title{
СИСТЕМНА БІОЛОГІЯ СТАРІННЯ: МОДЕЛЮВАННЯ МОЛЕКУЛЯРНИХ МЕХАНІЗМІВ РОЗВИТКУ ВІКОВИХ ЗАХВОРЮВАНЬ. КОНЦЕПТУАЛЬНИЙ АНАЛІТИЧНИЙ ОГЛЯД
}

\author{
О. П. Мінцер, В. М. Заліський \\ Національна медична академія післядипломної освіти імені П. Л. Шупика
}

\begin{abstract}
Феномен старіння включає групу взаємопов'язаних процесів, що відбуваються на організмовому, тканинному, клітинному та молекулярно-генетичному рівнях. Давно висловлювалося припущення, що старіння тісно пов'язано зі складною динамікою фрізіологічних систем, які підтримують гомеостаз і, зокрема з дерегуляцією регуляторних молекулярних мереж. У роботі представлено докази важливості динаміки таких складних систем при старінні й того, що фрізіологічна дерегуляція (поступове руйнування здатності складних регуляторних мереж підтримувати гомеостаз) є емерджентною властивістю цих мереж, що грає важливу роль у старінні. Завданням цього огляду є узагальнення наявних концепцій про основні детермінанти старіння та довголіття, а також розгляд тенденцій розвитку математичних моделей процесів старіння. Показано, що відсутність інтегрованих трансляційних досліджень на шляху розвитку системної медицини та системної біології є одним із основних фракторів, що обмежують надання сучасних засобів у вирішенні проблеми боротьби зі старінням. Серед основних фракторів старіння звернуто увагу на те, що вплив на мітохондрії представляється привабливою перспективою для досягнення покращання здоров'я та тривалості життя, оскільки омолодження старих мітохондрій може виявитися важливою терапевтичною стратегією для покращання здоров'я літніх людей. Постулюється також, що швидкість і простота інтеграції сучасних програмних комплексів для моделювання біологічних систем дозволяють дослідникам вивчати великі моделі, включаючи їх взаємодію в багатовимірних фрорматах із ансамблями невеликих моделей.
\end{abstract}

Ключові слова: системна біологія, старіння, молекулярні механізми, математичне моделювання.

\section{SYSTEMIC BIOLOGY OF AGING: MODELING THE MOLECULAR MECHANISMS OF THE DEVELOPMENT OF AGE-RELATED DISEASES. CONCEPTUAL OVERVIEW}

\author{
O. P. Mintser, V. M. Zaliskyi \\ Shupyk National Medical Academy of Postgraduate Education
}

Background. The phenomenon of aging includes a group of interrelated processes occurring at the organism, tissue, cellular and molecular genetics levels. It has long been suggested that aging is closely related to the complex dynamics of physiological systems that support homeostasis and, in particular, to the deregulation of regulatory molecular networks. The paper presents evidence of the importance of the dynamics of such complex systems during aging and the fact that physiological deregulation (the gradual destruction of the ability of complex regulatory networks to maintain homeostasis) is an emergent property of these networks that plays an important role in old age.

Purpose. The purpose of this review is to summarize the existing concepts about the main determinants of aging and longevity, as well as to consider the trends in the development of mathematical models of aging processes.

Results. Materials and methods. It is shown that the lack of integrated translational research in the development of systemic medicine and systemic biology is one of the main factors limiting the provision of modern means in solving the problem of anti-aging. Among the main factors of aging, attention is drawn to the fact that exposure to mitochondria is an attractive prospect for achieving improved health and longevity, since the rejuvenation of old, mitochondria can be an important therapeutic strategy for improving the health of older people.

Conclusion. It is also postulated that the speed and ease of integrating modern software systems for modeling biological systems allow researchers to study large models, including their interaction in multidimensional formats with ensembles of small models.

Key words: systems biology, aging, molecular mechanisms, mathematic modeling. 


\title{
СИСТЕМНАЯ БИОЛОГИЯ СТАРЕНИЯ: МОДЕЛИРОВАНИЕ МОЛЕКУЛЯРНЫХ МЕХАНИЗМОВ РАЗВИТИЯ ВОЗРАСТНЫХ ЗАБОЛЕВАНИЙ. КОНЦЕПТУАЛЬНЫЙ АНАЛИТИЧЕСКИЙ ОБЗОР
}

\author{
О. П. Минцер, В. Н. Залесский
}

Национальная медицинская академия последипломного образования имени П. Л. Шупика

\begin{abstract}
Феномен старения включает группу взаимосвязанных процессов, происходящих на организменном, тканевом, клеточном и молекулярно-генетическом уровнях. Давно высказывалось предположение, что старение тесно связано со сложной динамикой фризиологических систем, поддерживающих гомеостаз и, в частности с дисрегуляцией регуляторных молекулярных сетей. В данной работе представлены доказательства важности динамики таких сложных систем при старении и того, что физиологическая дисрегуляция (постепенное разрушение способности сложных регуляторных сетей поддерживать гомеостаз) является эмерджентным свойством этих сетей, играющим важную роль в старении. Задачей настоящего обзора является обобщение имеющихся концепций об основных детерминантах старения и долголетия, а также рассмотрение тенденций развития математических моделей процессов старения. Показано, что отсутствие интегрированных трансляционных исследований на пути развития системной медицины и системной биологии является одним из основных фракторов, ограничивающих предоставление современных средств в решении проблемы борьбы со старением. Среди основных фракторов старения обращено внимание на то, что воздействие на митохондрии представляется привлекательной перспективой для достижения улучшения здоровья и продолжительности жизни, поскольку омоложение старых митохондрий может оказаться важной терапевтической стратегией для улучшения здоровья пожилых людей. Постулируется также, что скорость и простота интеграции современных программных комплексов для моделирования биологических систем позволяют исследователям изучать большие модели, включая их взаимодействие в многомерных фрорматах с ансамблями небольших моделей.
\end{abstract}

Ключевые слова: системная биология, старение, молекулярные механизмы, математическое моделирование. 
Введение. Системная биология является многопрофильной областью, специализирующейся на разработке и усилении методов количественного анализа и методов вычислительного моделирования с целью сбора специфических знаний на основе экспериментальных данных, в том числе отражающих процесс старения [9, 11, 92]. Этот целостный подход к биологии сформирован вокруг идеи о том, что полное понимание биологической системы не может быть достигнуто без изучения ее в целом $[8,25]$. Подобное представление позиционирует системную биологию на контрасте с традиционными подходами, которые изучают отдельные части системы и, таким образом, могут упускать важные поведенческие ответы, возникающие в результате взаимодействия этих отдельных частей. Учитывая исключительную сложность «стареющего» фенотипа и большое разнообразие клеточных систем, на которые он оказывает влияние, совершенно очевидно, что всестороннее изучение процесса старения требует подчеркнутого внимания к системной биологии.

Регуляция биологических процессов старения и долголетия: молекулярные механизмы. Почти 30 лет назад в работе [67] была представлена попытка создания классификации теорий старения на основе более чем 300 их вариантов. Принципиальной и тогда и сегодня является дискуссия о существовании единого (центрального) механизма старения [14]. Очевидны как теоретические, так и эмпирические доказательства наличия взаимосвязей между механизмами старения [1]. Тем не менее, исследователи не пришли к общему консенсусу того, как эти взаимосвязи между механизмами инициируют процесс старения [46].

Общепризнано, что феномен старения представляет мощный комплекс взаимосвязанных процессов, происходит на всех уровнях биологического организма: организменном, тканевом, клеточном, молекулярно-генетическом. Комплекс включает регуляцию процессов поддержания гомеостаза, метаболических реакций, передачу внутри и межклеточных сигналов, накопление неспособных к делению клеток, поврежденных органелл и наномолекул, эпигенетические изменения, генетическую нестабильность и многие другие процессы [63].

Организменный уровень старения включает в себя неспособность поддерживать постоянство внутренней среды организма, функциональные расстройства и повышение восприимчивости к возрастным заболеваниям [48]. Эти преобразования часто связаны с изменением количества клеток и качественного состава тканей, нарушением механизмов межклеточной сигнализации и активности систем ответа на стресс и метаболическими изменениями.

На тканевом уровне хроническое воспаление (inflammation) выступает драйвером многих возраст-зависимых заболеваний, прежде всего, сердечно-сосудистых и нейродегенеративных [6]. Нарушается регуляция нутриент -зависимого метаболизма. У стареющего организма изменяется регуляция метаболических путей, ассоциированных синсулин/инсулиноподобным факторомроста(IGF)-1, сиртуинами, 5-АМР-активируемой протеинкиназой (AMPK) и мишенью рапамицина (MTOR).

Нарушение работы клеток - еще один уровень, на котором происходит старение. С возрастом увеличивается количество неспособных к делению (сенесцентных) клеток; усиливается образование активных форм кислорода (АФК) в результате снижения активности митохондриальной дыхательной цепи и антиокислительных ферментов, запуская ответ на денатурацию белков в сети эндоплазматического ретикулума, а также возникает неспособность клеток усиливать поврежденные белки и поддерживать протеостаз [99, 104].

На молекулярном уровне старение проявляется неспособностью клетки полностью восстанавливать поврежденные наномолекулы. При старении накапливаются поврежденные участки ДНК [64], аккумулируются эпигенетические модификации ДНК и гистонов [5], приводящие к перестройке хроматина. При этом происходит гетерохроматизация важнейших для жизнедеятельности клетки участков хромосом (SAHF, старение - ассоциированный гетерохроматин) [25] и дегетерохроматинизация повторяющихся последовательностей генома, ведущая к генетической нестабильности [5].

Известно также, что стрессоустойчивость связана с долголетием. Повышение стрессоустойчивости приостанавливает рост и репродукцию у животных. В качестве побочного эффекта происходит замедление процессов старения. Гормоны оси GH/IGF-1 и контролируемые ими сигнальные пути (рецептор IGF-1 и его субстраты, киназа PISK, AKT, mTOR, SGK) в благоприятных условиях окружающей среды обеспечивают процессы роста и размножения организма, подавляя при этом эноргозатратные процессы стрессоустойчивости. 
Одним из путей индукции программы стрессоустойчивости является активация генов стрессответа, многие из которых играют ключевую роль в реализации долгожительства. К ним можно отнести гены кодирующие факторы транскрипции FOXA, NRF2, HIF-1, киназу JNK, сиртуины и ряд других белков [90]. В условиях стрессовой нагрузки индукция FOXO вызывает экспрессию генов клеточной защиты, таких как ген белка теплового шока Hsp70, ген репарации ДHK GADD45, ген аутофагии LC 3B, GABARAPL 1 и Atg12 [22], лизосомальный ген LAMP1, а также гены убиквитин - протеосомной деградации белков.

Цель работы: обобщение имеющихся концепций об основных детерминантах старения и долголетия, а также рассмотрение тенденций развития математических моделей процессов старения.

Результаты и их обсуждение. Реализация функции FOXO регуляции белков происходит с участием многих других генов, ассоциированных с долголетием, например, AMPK, PGC1 $\alpha$, p53, SIRT1, SIRT6, NRF 1, SREBP 1, которые задействованы в биогенезе митохондрий, гликолизе, митофагии, митогормезисе [34].

Регулятор старения ядерный фактор NRF2транскрипцый регулятор более чем 500 генов, главным образом отвечает за антиоксидантную защиту, детоксикацию ксенобиотиков и токсичных металлов [72]. Отмечено, что активность компонентов сигнального пути NRF2 положительно коррелирует с максимальной продолжительностью жизни. При этом для его негативного регулятора Keap1, выявлена обратная тенденция. Активация NRF2 отмечена при использовании средств профилактики и лечения сердечно-сосудистых заболеваний (СС3), почек, легких, метаболических и аутоиммунных расстройств, хронического воспаления, злокачественных новообразований в старости [72].

Транскрипционный фактор HIF-1 индуцируется в ответ на гипоксию и регулирует экспрессию генов противогипоксических факторов стимулируя рост микрососудов и активацию тромбоцитов, транспортную функцию крови, сдвиг в сторону анаеробного метаболизма за счет снижения потребления митохондриями кислорода, а также контроль транспорта глюкозы и гликолиза при старении [44].

Сиртуины - семейство никотинамид адениндинуклеотида (NAD+)-зависимых ферментов, обладающих диацетилазной и
АДФ-рибозил-трансферазной активностью. Активность диацетилазы SIRT1 индуцируется при увеличении внутриклеточного соотношения NAD+NADH в ответ на окислительный стресс в процессе старения. Гомолог SIRT1 у безпозвоночных и дрожжей ответственен за позитивный эффект влияния ограничения калорий на продолжительность жизни [20]. SIRT1 является ключевым регулятором физиологических процессов, связаным с возраст-зависимыми процессами, в частности с сахарным диабетом 2-го типа, ожирением, нейродегенеративными расстройствами и новообразованиями [48], а также играет важную роль в таких процессах как апоптоз. Другой представитель семейства сиртуинов SIRT6 стимулирует активность различных белков репарации ДНК в ответ на стресс [61]. SIRT6 подавляет генетическую нестабильность, связанную с активацией ретротранспозона LINE-1.

JNK — это эволюционно консервативная протеинкиназа активируемая в старости в ответ на влияние стресс-факторов. С одной стороны, JNK индуцирует активацию генов, обеспечивающих защиту клетки от негативных влияний путем повышения активности факторов трансдукции FOXO и AP1; а с другой стороны влияет на клеточный метаболизм, рост и деление через инсулиновую IGF-1 сигнализацию [15]. Нарушение регуляции JNK приводит к развитию нейродегенеративных заболеваний, метаболических расстройств и новообразований.

Инсулиновый фактор роста-1 (IGF1) и соматотропин (GH) являются стимуляторами роста. Гормон-рецепторный комплекс (GH/GHR), обладающий протеинкиназной активностью, активирует путь JAK/STAT сигнализации и стимулирует экспрессию IGF-1. Циркулирующий в крови фактор роста IGF-1 взаимодействует с рецептором IGF-1R на поверхности клеток переферических тканей. Рецепторы траесдуцируют сигнал к белкам IRS, передающим далее сигнал на киназы PI3K, AKT/PKB и mTOR [83]. С другой стороны, как уже отмечалось, происходит деактивация энергозатратного процесса поддержания стрессоустойчивости стареющих клеток.

TGF- $\beta$-сигнализация вовлечена во многие клеточные реакции, такие как рост, дифференциировка, апоптоз, поддержание гомеостаза [12]. TGF-ß1 обеспечивает индукцию генов-маркеров клеточного старения и участвует в формировании сенесцентного фенотипа клеток в условиях стресса. 
Физиологический ответ на поступление питательных веществ - одно из наиболее изучаемых явлений в биологии старения [96]. Важнейшую роль при этом играет специфический путь (Rheb/mTOR/SGK/SG/4E-BP/eIF-4E), который состоит из двух ветвей, регулируемых комплексами mTOR и mTORC2. Первый из них отвечает за регуляцию трансляции (активирует р70, S64, S6, eIF-4E и репрессирует ингибитор трансляции $4 \mathrm{E}-\mathrm{BP})$, биогенез рибосом, подавление аутофагии, осуществление гликолиза (HIF-1), васкуляризацеей (VEGF), а также - синтез жирных кислот (SREBP) [33].

mTORC2 участвует в перестройке активного скелета, однако ингибирует транскрипционные факторы стресс-ответа FOXO1 и FOXO3 при участии комплекса AKT-PKC-S6K, а также активирует фактор транскрипции NF-kB, провоцируя воспаление канцерогенез и клеточное старение [35].

K положительным регуляторам продолжительности жизни относятся мембранные корецепторы рецепторов фактора роста FGF ( $\alpha$ и $\beta$-Klotho), которые индуцируют уровень гормона роста, IGF-1 и чувствительность тканей к инсулину [38]. При отклонении гена Klotho у животных (мыши) появляются признаки ускоренного старения, такие как остеопороз, атеросклероз, эмфизема легких, что приводит к сценарию ранней гибели. При нехватке Klotho отмечено нарушение минерального обмена, включая гиперкальцимию, гиперфосфатемию и гипервитаминоз Д.

Другим примером белков, способствующих долгожительству и регулирующих метаболизм в старости, является АМРК (АМФ-активируемая протеинкиназа), запуск которой триггеризирует повышение соотношения АМФ/АТФ в результате энергетического голодания клетки, а также - нарушения митохондриального дыхания и гипоксии [18].

АМРК управляет рядом метаболических путей, например, поглощением и утилизацией глюкозы, окислением липидов [16] и связана с влиянием активаторов АМРК (метформин, фенформин) на увеличение продолжительности жизни.

PPARs-рецепторы, активируемые пероксисомами пролифераторами, относятся к группе ядерных, регулирующих процесс транскрипции. PPAAR aктивирует ряд генов, отвечающих за метаболизм нитритов и поддержание уровня глюкозы. Этот белок ответственен за развитие связанной со старением невосприимчивостью к инсулину и участвует в ингибировании хронического воспаления, которое сопровождает процесс старения [59].

Поддержание целостности генома при старении связано с активностью фермента полимеразы поли(АДФ-рибозы) 1 (РАРР1), является сенсором разрывов цепей ДНК [71]. Другими важнейшими сенсорами двунитиевых и однонитиевых повреждений ДНК является ATM и ATR киназы, которые обеспечивают запуск проверочных (конечных) точек клеточного цикла, инициацию задержки клеточного цикла и репарацию ДНК. Они фосфорилируют ключевые белки сигнальных путей при ответе на ДНК повреждение при старении, включая p53, Chk1, Chk2, Mdm2, NSB1, AMPК сигнализацию. Одной из важнейших мишеней этих киназ является фактор транскрипции р53. Его активация необходима для реализации стресс-реакций при клеточном старении (от остановки клеточного цикла и репарации ДНК до клеточной гибели (апоптоза).

В поддержке целостности генома большое значение также имеет активность теломеразы. Она представляет собой обратную транскриптазу и отвечает за синтез теломерной ДНК, укорачивающейся при каждом делении зрелых соматических клеток. Несмотря на то, что данные о корреляции длины теломер с продолжительностью жизни и скоростью старения противоречивы, установлено, что при ССЗ человека обнаруживается значительное укорочение теломер в клетках сосудистого эндотелия, а генотерапевтическая активация теломеразы у взрослых животных обеспечивает кардиопротекцию [13].

Протеостаз - совокупность механизмов, обеспечивающих контроль качества клеточных белков. Нарушение протеостаза является биомаркером старения [23] и оказывает негативное влияние на продолжительность жизни. Снижение экспрессии шаперонов, в частности белков теплового шока (HSPs) и их основного регулятора - фактора теплового шока (HSP) 1 негативно влияет на продолжительность жизни и устойчивость к стресс-факторам на фоне увеличения образования белковых агрегатов.

За процессы утилизации как избыточных, так и поврежденных белковых фрагментов клеток ответственных убиквитин - протеасомная и аутофагическая системы через протеосомы и лизосомы, соответственно. Повышению их активности защищает клетки от протеотоксического стресса и поддерживает клеточный гомеостаз в процессе старения [86]. 
В детоксикации конечных продуктов гликирования (AGEs) решающую роль играет глиоксалазная система, активность рецепторов RAGE и зависимая от RAGE активация провоспалительного транскрипционного фактора NF-kB. Связывание RAGE с их лигандами AGE3 запускает сигнальные пути, способствующие старению и развитию различных возрастных патологий в частности ожирения, диабета 2-го типа, хронического воспаления, болезни Альцгеймера, злокачественных новообразований [84].

Ключевыми белками митохондрий, влияющими на процесс старения, организма являются TFAM и PGC12. Транскрипционный фактор митохондрий A(TFAM) играет важную роль в поддержании количества и качественного состава митохондрий. Он обеспечивает упаковку тДНК в митохондриальные нуклеотиды, регулирует репликацию и репарацию нтДНК [62]. Отмечено, что с возрастом снижается экспрессия гена TFAM, а также способность его белка связываться с этим нтДНК [77].

Сигнальные молекулы гормонов, выделяемых жировой тканью, называют адипокинами; к ним относятся: адепонектин, лептин, резистин, TNF- $\alpha$, IL-6/PAI-1. Эти молекулы связаны со многими сигнальными путями клетки, определяющими старение организма. Так низкий уровень адипонектина в плазме крови у человека указывает на развитие хронической ишемической болезни сердца и может служить маркером преждевременного старения ССС [26].

Другим примером ассоциированных со старением цитокинов является миостатин. Миостатин - семейство трансформирующих ростовых факторов, который быстро подавляет рост и дифференцировку мышечной ткани во время старения, что приводит к различным заболеваниям [68].

Селекция жизнеспособных клеток при старении тесно связана с механизмами программированной клеточной гибели - апоптозом. Постепенное накопление сенесцентных клеток в тканях ускоряет старение организма. Их количество в молодом организме регулируется иммуноклиренсом, способность к которому угасает с возрастом из-за старения иммунной системы [100]. Одним из регуляторов апоптоза в стареющих клетках является сигнальный каскад Shc/Ras. У млекопитающих три изоформы Shc (p52Shc, p46Shc и p66Shc) отвечают за подавление апоптоза и регуляцию продолжительности жизни, а такие изоформы Shc как p52Shc и p46Shc передают и усиливают сигнал от рецепторных тирозинкиназ к белкам Ras.
Ras представляют собой небольшие ГТФазы, которые участвуют в трансдукции сигналов от рецепторных тирозинкиназ к сигнальным путям клетки, отвечающим за апоптоз и выживание стареющих клеток [39]. К таким путям относится сигнальный каскад митоген-активируемых киназ (MAPK) и киназ (ERK), регулирующих передачу в клетку внеклеточных сигналов. Установлено, что липидактивация генов семейства Ras является причиной развития трети злокачественных новообразований, которые с трудом поддаются противоопухолевой терапии [39].

Известно, что гены циркулирующих ритмов (околосуточные колебания различных физиологических показателей) и их продукты обмена включены во многие процессы, сопряженные со старением организма и, в том числе, с возрастными патологическими состояниями [89]. При нормальном старении отмечаются нарушения циклов сна и бодрствования, сон становится деконсолидированным, в свою очередь осцилляции экспрессии генов циркадных ритмов теряют робастность, а экспрессия изменяет амплитуду или фазу с утратой способности к колебаниям. Так, белок суточного ритма BMAL1 контролируемый соответствующим геном, влияет на скорость старения, при взаимодействии с комплексами сигнального каскада mTOR. Белок CLOOK активирует провоспалительный фактор NF-kB, сохраняющий продолжительность жизни, а сверх экспрессия Timeless Cryptochrome снижает скорость старения. Все эти изменения инициируются строго иерархичной системой молекулярных осцилляторов, основанной на функционировании транскрипционно-трансляционных либо трансляционно-трансляционных петель биологической обратной связи.

Физиологическая дисрегуляция при старении и моделирование молекулярных механизмов возраст-зависимых процессов. Уже давно высказываются предложения, что старение тесно связано со сложной динамикой физиологических систем, которое поддерживают гомеостаз и, в частности, с дисфункцией регуляторных сетей молекул сигнальной трансдукции. В последнее время подчеркивается важность такой сложной динамики систем в процессе старения. Имеются важные доказательства того, что физиологическая дисрегуляция (постепенное нарушение способности сложных сетей поддерживать гомеостаз) является эмерджентным свойством сложных сетей и играет важную роль в процессе старения. 
Наряду с расширением роли системной биологии или старения [103], активно разрабатываются такие направления как: динамика сложных систем в процессе старения [24]; многофакторные теории старения [45]; общее направление развития системной биологии и биоинформатики старения [90]; системная робастность при старении [55]. Каждое из этих направлений исследований (окончательно не разработанных) подчеркивает сложность самого процесса старения и допускает их интеграцию в долгосрочной перспективе.

Старение также может быть многофакторным процессом, основанным на накоплении альтерационных изменений, но не сопряженными со сложной системной динамикой [45]. Поэтому различия между многофакторными теориями и тенденциями сложных систем могут иметь важное значение для эволюционирования процесса старения [102]. Обоснование роли сложных систем (в процессе возрастных изменений) подразумевает взаимодействие между подсистемами и это включает сложные петли биологической обратной связи, когда проблемы в одной системе вызывают новые проблемы в другой [40].

Одни исследователи делают акцент на компьютерном моделировании динамики процесса старения, основанном на детальном знании структуры системы (не придавая особого внимания ее свойствам) [45], в то время как другие работают в области сетевой картографии («Map networks») [43], что позволяет использовать функциональную основу технологий высокой пропускной способности для создания целевой интеграции больших массивов данных возрастных изменений. Еще один подход позволяет интегрировать структурную динамику и функцию путем использования принципов проектирования сложной сетевой динамики систем в старости [24].

Одной из гипотез сетевого подхода к анализу сложных возрастных изменений является понятие точности (прецизионность «precision»), которая необходима для успешного понимания сетевой динамики [74], позволяющая детализировать линейные и логистические функции регуляторных сетей. Другим направлением исследований сложности («complexity») системы старения является робастность (устойчивость) - свойство, позволяющее системе поддерживать свои функции в ответ на внутренние и внешние пертурбации (возмущения «perturbatio») [49]. Эта гипотеза предполагает, что под эволюцией робастности подразумевается эволюция компромиссов в высокооптимизированных системах, а старение может быть побочным эффектом многочисленных аспектов эволюционной оптимизации развития систем на уровне организма [85].

Наконец, потеря сложности («loss of complexity») системы старения является еще одной гипотезой, которая отражает понимание организма как сложной системы [60]. Потеря «сложности» в старости позволяет регистрировать в организме фрактальные паттерны, а также хаотические (сильно изменяющиеся флуктуации) или сложные сочетания структурных изменений. При этом стареющий организм теряет контроль над многомерными состояниями и динамическими процессами, лежащими в основе сложной организации систем. Однако потеря сложности системы старения не обязательно связана с сетью молекулярных взаимодействий. Например, с возрастом привычными предметами loss of complexity являются вариабельность сердечного ритма и нарушения ветвления микрососудистой сети [75], что приводит к нарушению способности адаптироваться к физиологическому стрессу. В будущем раскрытие тонкого механизма loss of complexy, основного на тенденции хаоса, и связанной с ней геометрической концепцией фракталов, могут обеспечить новые способы мониторинга старения и проверки эффективности конкретных вмешательств для изменения возраст-зависимого снижения адаптивной способности [76].

Многие исследования молекулярных механизмов старения сосредоточены на конкретной теории, такой как накопление соматических мутаций, укорочение теломер, повреждение белка или митохондриальная дисфункция. Однако в конце1990-х годов было осознано, что отдельные механизмы не могут адекватно объяснить процесс старения [50] и необходимо рассматривать взаимодействие между этими различными механизмами (рис. 1).

Например, в результате повреждения митохондрии производят больше АФК (ROS), которые, в свою очередь, приводят к альтернативным изменениям практически всех молекулярных компонентов - это способствовало тому, что сетевая теория старения и проблема изучения сложных взаимодействий инициировали одну из первых интегрированных математических моделей старения [84]. С тех пор появилось много новых технологий и возможностей получения больших массивов данных, что потребовало ускоренной 


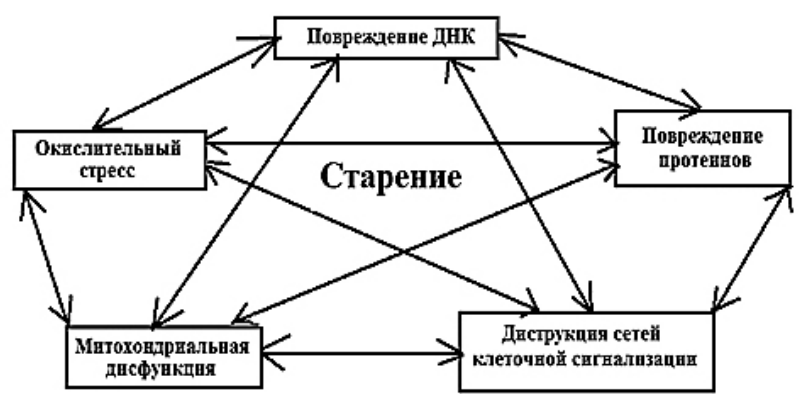

Рис. 1. Взаимодействие молекулярных механизмов старения. Схематически представлены примеры некоторых основных механизмов и их взаимодействий

разработки новых инструментов анализа и интерпретации, которые оптимизировали процесс появления новых областей системной биологии $[25,46]$.

Хорошей практикой моделирования процессов старения явилось представление моделей с кодировкой в формате SBML («system biology marked language») для осуществления архивирования в BioModels [21]. BioModels - онлайн база данных (http://www.ebi.ac.uk) (biomolecules-main), в которой хранятся сведения о молекулах, связанных со старением с присвоением каждой модели уникального идентификационного кода (табл. 1).

Таблица 1

\section{Модели, связанные со старением и архивируемые в базе данных BioModels [21]}

\begin{tabular}{|l|l|}
\hline \multicolumn{1}{|c|}{ Модель } & База BioModel \\
\hline Моделирование действия маркеров при старении & BIOMD 0000000091 \\
\hline Математическая модель метаболизма глутаргина & BIOMD 0000000268 \\
\hline Обратная связь между 21 и продукцией АФК в процессе клеточного старения & BIOMD 0000000287 \\
\hline $\begin{array}{l}\text { Математическая модель развернутого белкового стресс-ответа при старение- } \\
\text { ассоциированного развития адаптации и апоптоза }\end{array}$ & BIOMD 0000000446 \\
\hline $\begin{array}{l}\text { In vivo in silico анализ убиквитилирования РСVA } \\
\text { в активации пути восстановления пострепликации у S/сегеvіsiaе }\end{array}$ & BIOMD0000000475 \\
\hline $\begin{array}{l}\text { Модель кооперативной взаимосвязи между электрической активностью мозга, } \\
\text { метаболизмом и гемодинамикой в старости }\end{array}$ & BIOMD0000000570 \\
\hline $\begin{array}{l}\text { Моделирование вмешательств для улучшения возрастной потери костной } \\
\text { ткани }\end{array}$ & BIOMD0000000612 \\
\hline $\begin{array}{l}\text { In siliсо модель системы убиквитин-протеасомы, включающая нормальный } \\
\text { гомеостаз и возрастное снижение системы }\end{array}$ & BIOMD0000000105 \\
\hline $\begin{array}{l}\text { Моделирование колебаний изменчивости } \\
\text { в системе р53 - Мдт 2 при старении }\end{array}$ & BIOMD0000000189 \\
\hline $\begin{array}{l}\text { Математическая модель метаболизма холестерина и } \\
\text { его возрастной дисрегуляции }\end{array}$ & BIOMD0000000434 \\
\hline $\begin{array}{l}\text { Стохастическая модель агрегации, нарушения деградации и иммунного тарге- } \\
\text { тирования димеров бета-амилоида при болезни Альцгеймера }\end{array}$ & BIOMD0000000462 \\
\hline $\begin{array}{l}\text { Математическое моделирование провоспалительных цитокинов при ревмато- } \\
\text { идном артрите в старости }\end{array}$ & BIOMD0000000054 \\
\hline $\begin{array}{l}\text { Динамическое моделирование сигнальных путей при клеточном старении по- } \\
\text { зволяет выявить стратегии адресных вмешательств }\end{array}$ & BIOMD0000000582 \\
\hline $\begin{array}{l}\text { Моделирование реакции факторов транскрипции FОХО на множественные } \\
\text { пострансляционные модификации, контролируемые старение- } \\
\text { ассоциированными путями }\end{array}$ & MODEL 1112260002 \\
\hline
\end{tabular}


Модели повреждения и восстановления ДНК. Многие модели предложены для исследования роли повреждения ДНК на уровне клеточного старения в культуре фибробластов [3, 47]. Эти модели не включают особенности механизмов двунитиевых разрывов ДНК, в соответствии с которыми активизируются клеточные сигнальные пути (ATM/ATR p53, p21), что приводит к задержке клеточного цикла. Однако математическое моделирование выявило связь таких событий с наличием петель отрицательной обратной связи в системе p53, а также между р21 и продукцией АФК [37, 73]. Экспериментальное подтверждение того, что АФК функционирует также в составе петли положительной обратной связи для активации и поддержки клеток в фазе репликативного старения [7, 73].

Создание моделей репарации ДНК в основном мотивировано необходимостью оптимизации адресной терапии злокачественных новообразований [71]. На основе экспериментальных данных, полученных при уү-облучении фибробластов человека, стохастическая модель NHEJ («nonhomogous and joining) - сигнализации показала важность редоке-регуляции белков (Ku 70 и Ku 80), которые образуют гетеродимеры для связывания участков двунитиевых разрывов ДНК [31]. В последующем, интеграция с моделью однонитиевых разрывов ДНК позволила спрогнозировать пути восстановления повреждений ДНК в процессе клеточного старения [10, 32]. Хотя обе модели были закодированы в формате SBML, их преобразования, благодаря новым правилам архивирования в BioNetGen, позволило оценить влияние ү-облучения на репарацию ДНК-повреждений и индукцию клеточного старения [65].

Модели укороченных теломер. Известно, что повторяющиеся последовательности ДНК, защищающие концы линейных хромосом (теломеры) в соматических клетках человека, сокращаются с каждым последующим клеточным делением (из-за отсутствия концевой репликации). Первые математические модели укороченных теломер (как репликативного клеточного старения, предел Хейфлика) были экспериментально подтверждены [95] и показали, что окислительный стресс является важным фактором, способствующим на порядок укорочению теломеров линейных хромосом [78]. Авторы высказали предположение [78], что результат репликативного клеточного старения зависит не только от исходной (критической) длины теломер, а обусловлен индукцией образования так называемых «расщепляющих» Т-петель биологической обратной связи. Другие исследователи [93] на основании анализа стохастической модели клеточного старения считают, что стохастические вариации, наблюдаемые в репликативной продолжительности жизни отдельных клеток в культуре, зависят также от влияния взаимодействия разных элементов стохастической сети, окислительного стресса, а также соматических мутаций в ядерной митохондриальной ДНК.

Модели протеостаза и шаперонинга. Белковый гомеостаз поддерживается так называемыми системами «контроля качества» (такими как синтез белка, фолдинг, ре-(ан) фолдинг) [56]. Протеины очень чувствительны к окислительному повреждению, что приводит к их конформационным (обратимым) или ковалентным (необратимым) изменениям. Конформационные изменения обратимы благодаря молекулярным шаперонам, которые связываются гидрофобными поверхностями и помогают в рефолдинге. Оказалось, что шапероны, могут также участвовать в секвестрации (sequestration) поврежденных белков, а клеточное старение расценивается, как состояние, обусловленное шапероновой перезагрузкой и протеотоксичностью («proteotoxicity») [42]. Стохастическое моделирование действия шаперонов (Hsp70/Hsp 90) и их роли при старении показало, что шаперонинг способен поддерживать белковый гомеостаз в условиях слабого или переходного стресса [79].

Тем не менее, хронический стресс в конечном итоге приводит к тому, что баланс между шаперонами и неправильно собранными белками отсутствует, а данные белки образуют агрегаты. Расширение моделирования в направлении апоптоза показало, что клетки с высоким уровнем содержания неправильно собранных белков могут развиваться согласно сценарию запрограммированной клеточной гибели [80].

Две системы клетки (аутофагическая и протеосомная) участвуют в устранении поврежденных белков. Использование in silico модели функционирования убиквитин-протеасомной системы (включающей нормальный и возраст-зависимый гомеостаз) позволило спрогнозировать увеличение содержания агрегированного протеина и снижение гомеостаза протеинов с возрастом. Аутофагическая система включает в себя макро-аутофагию и шаперон-опосредованную аутофагию (ШОА), которые подвержены функциональному снижению в старости [19]. Активация ШОА регулируется 
окислительным стрессом в целях селективной деградации и удаления окисленных цитозольных белков лизосомами. Математическая модель перекрестного взаимодействия между аутофагией и апоптической сигнализацией выявила то, как разные уровни стресса определяют процесс переключения между двумя сценариями клеточной судьбы [97].

Модели митохондриального старения. Особое место занимают теории, согласно которым митохондриям принадлежат основные роли в процессе старения. На протяжении последних 50 лет митохондриям принадлежало центральное место в лидирующей гипотезе, известной как свободнорадикальная теория. Роль митохондрий подчеркивается их главенствующей ролью в гомеостазе клеток практически всех тканей. Таким образом, насколько можно судить по описанию молекулярных и клеточных механизмов, митохондрии вовлечены в каждый из важных аспектов старения: угасание функций стволовых клеток, физиологическое старение клеток, «inflame-aging » (возрастное хроническое системное воспаление) и многие другие. Важнейшая роль митохондрий изучался для функционирования скелетной мышечной ткани и ткани сердца, так как саркопения (возрастная деградация мышц) и сердечная недостаточность являются двумя основными причинами ухудшения физического состояния пожилых людей. Не только в этих двух тканях, но и в других, в том числе в тканях печени, головного мозга и в жировой ткани в процессе старения выявляются митохондриальные нарушения.

Согласно митохондриальной свободнорадикальной теории старения, окислительное повреждение мтДНК является основным механизмом, оказывающим влияние на белки дыхательной цепи, индуцируя нарушение ее функций и повышая продукцию АФК, что формирует своеобразный «порочный круг». Однако эта теория подверглась серьезным сомнениям и научному сообществу пришлось адаптировать рабочие гипотезы таким образом, чтобы они соответствовали более сложным переплетениям механизмов старения, центральным звеном которых являются митохондрии [107].

Математическое моделирование динамики митохондриального старения позволило проанализировать гомеостатические механизмы, регулирующие уровни АФК и функционирование митохондрий [52]. Авторы [36] разработали комплексную вычислительную модель, охватывающую производство митохондриальных АФК в различных состояниях энергетики митохондрий, определяемых ритмом сердца. Моделирование помогло установить взаимосвязь между дисфункциональной выработкой ионов кальция и повышенной продукцией АФК митохондриями, в результате повышения уровней цитозольного натрия, выявленного в стареющих кардиомиоцитах [36]. Установлено [73], что петля биологической обратной связи между активацией p21 и продукцией АФК, которая триггеризировалась реакцией повреждения ДНК, способствовала формированию состояния «глубокого» клеточного старения. Такое состояние было связано с активацией гена СДКN1А (p21), которая продуцировала митохондриальную дисфункцию и продукцию AФК через GADD45-MARK14 (p38 MARK) GRB $\alpha$ - TGF $\beta R 2-T G F$ beta сигнализацию. Авторы считаю, что эта петля необходима и достаточна для обеспечения устойчивости фенотипа старения [73].

Одним из подходов системной биологии к клеточному старению является динамическое моделирование сетей множественной сигнализации сразу несколькими петлями биологической обратной связи на клеточном уровне [30]. При этом двойное ингибирование mTOR подтвердило прогноз вычислительной модели о возможности уменьшения индуцированной старением митохондриальной дисфункции и количества двунитиевых разрывов ДНК. Это позволило также охарактеризовать чувствительность сетей стареющих клеток, определить место сигнального «шума», а также модифицировать стратегии целенаправленных вмешательств для торможения процесса старения.

Существуют вычислительные модели, которые связаны со старение-ассоциированным накоплением повреждений митохондрий. Например, математическое моделирование было использовано для того, чтобы продемонстрировать, что поврежденные митохондрии способствовали нарушениям энергетического метаболизма миоцитов [51]. Вычислительное моделирование также позволило осуществить анализ взаимодействий между ограничением пищевых калорий и метаболизмом митохондрий [69]. При этом удалось подтвердить экспериментальные результаты о том, что ограничение пищевых калорий может способствовать замедлению скорости митохондриального оборота в процессе старения гепатоцитов.

Модели дисрегуляции клеточной сигнализации. Ser/THR киназа и mTOR существует в двух 
структурно и функционально различных комплексах (mTORC1 и mTORC2), представляющих собой высокоинтегрированные сигнальные узлы. C возрастом многочисленные белки в сети mTOR становятся дисрегулированными [30]. Интеграция динамической сетевой модели ITOR с математической моделью клеточного старения позволила выявить потенциально новые подходы для торможения старения клетки [30]. Связи между mTOR и инсулиновой сигнализацией были положены в основу создания математических моделей тестирования механизмов инсулинорезистентности адипоцитов человека [17] с определением петли биологической обратной связи между mTOR и инсулиновой сигнализацией при сахарном диабете I типа.

Семейство транскрипционных факторов FOXO («Fork head box O protein») играет ключевую роль при старении. Динамические модели, которые фокусируются на старении, часто включают белки FOXO и их взаимодействие с сетью MTOR как части моделей [21]. Подробно смоделированы посттрансляционные модификации белков FOXO, а в исследовании [21] изучено влияние АФК на процессы активации и транслокации FOXO. При этом отмечено, что при низком окислительном стрессе повышение регуляции FOXO способствует росту антиоксидантной защиты, тогда как при хроническом окислительном стрессе выявляется снижение регуляции FOXO и торможение отсрочки начала старения.

Расшифровка особенностей TGF. $\beta$-сигнализации ускорила разработку моделей клеточного старения. Так в работе [65] представлена первоначально созданная модель TGF-сигнализации, которая показала, что рецепторы TGF являются не только преобразователями сигналов трансдукции, но ключевыми модуляторами реакции TGF. $\beta$ сигнализации. Модель [63], детализируемая изменениями рецепторов TGF. $\beta$ с течением времени показала, они способствуют развитию артрита у пожилых. Авторы, считают, что понимание динамики рецепторов, а также того, как они изменяются с возрастом, имеет большое значение для многих заболеваний и вычислительное моделирование может играть первостепенную роль в анализе этого процесса.

Сигнализация NF-KB опосредует экспрессию генов, влияющих на ряд биологических процессов, включая иммунитет, воспаление, дифференцировку клеток, апоптоз, клеточное старение, которые активируются целым рядом стимулов, включая инфекции АФК и возраст-ассоциированное повреждения ДНК [98]. Повышение активности NF-KB связано с появлением болезней старения (возрастных заболеваний), в то время, ингибирование NF-KB обуславливают отсроченное появление возрастных заболеваний. Моделирование клеточного старения на основе нечеткой логики с использованием защитных контуров отрицательной обратной связи и петлевых мотивов, опосредованных стрессовыми реакциями, позволило рассматривать сценарии оптимизации продолжительности жизни благодаря анализу молекулярных механизмов и динамики изменений клеточной сети, лежащих в основе формирующегося воспалительного фенотипа старения [54].

Цитокиновая сигнализация имеет решающее значение в регуляции иммуновоспалительных реакций при старении. Авторы [81] разработали модель, которая детализирует взаимодействия IL-1 и онкостатина M (OSM), что позволило исследовать, как синергия между ними приводит к интенсивному разрушению хрящевой ткани у животных.

Модели эпигенеза. Растёт число подтверждений того, что состояние метилирования ДНК (эпигенетический процесс) и клеточное старение неразрывно связаны. Так статистический анализ данных метилирования ДНК и байесовское моделирование позволили оценить время начала болезни у пациентов с пищеводом Барретта [28]. При этом «молекулярные часы» определяют возраст гетерогенных тканей при болезни Барретта, являющейся метапластическим предшественником аденокарциномы человека и как своеобразный биомаркер помогает контролировать риск развития злокачественного процесса, благодаря отслеживанию возрастного метиломного дрейфа («methylomic drift»). Авторы постулируют, что дифференциация метиломного дрейфа в клетках с метаплазией позволяет осуществлять количественную оценку периода времени, в течение которого у пациента развивается болезнь пищевода Барретта с переходом в злокачественных процесс.

Однако, биохимические и молекулярные процессы, участвующие в регуляции эпигенетических событий метилирования ДНК многогранны и исключительно сложные. Формирование более глубокого понимания этих процессов представляется весьма сложной задачей. Например, энзим-опосредованные события, ответственные за возрастной метиломный дрейф, пересекаются с фолат/фолиевой кислотой, 
роль которых в одноуглеродном метаболизме, связанном с метилированием ДНК (FOCM, «folat one carbon metabolism») довольно существенна [27]. Кроме того, было отмечено, что FOCM и метилирование ДНК зависят от других факторов, связанных со старением. Например, как на FOCM, так и на метилирование ДНК оказывает влияние окислительный стресс [66]. Кроме того, активность ДНК-метилтрансферазы 1 (DNMT 1), ключевого фермента ответственного за пострепликационный процесс переноса метильных групп в молекулу ДНК, модифицируется под влиянием сиртуина-1 (Sirt-1) [75].

Создание динамической модели метилирования/ демитилирования ДНК, основанной на активности белков DNMT с добавлением белков семейства Tet (ферментативно преобразовывающих метилцитозин в гидроксиметилцитозин), позволило оптимально точно предсказать экспериментально подтверждённые изменения количества полнофункциональных белков DNMT и Tet в клетке и обеспечить точное прогнозирование основных эпигенетических процессов, связанных с модификацией ДНК при гематологических злокачественных новообразованиях в старости [66]. Использование стохастической модели для изучения возрастных изменений метилирования ДНК в гемопоэтических клетках позволило выявить активизацию самонаведения молодых гемопоэтических стволовых клеток в нишах костного мозга, замедляющую эпигенетическое старение [82].

Математическое моделирование сыграло уникальную роль в оценке динамики влияния микроРНК (регуляторов эпигенеза) в управлении процессами клеточного старения, регулирующих белоккодирующие гены через посттранскрипционную репрессию. В частности, моделирование помогло выявить петли биологической обратной связи в сетях, опосредованных микроРНК и выявить взаимодействия между ними при регуляции генов [58].

В аспекте клеточного старения разработана математическая модель регуляции с помощью микроРНК систем внутриклеточной сигнализации при злокачественных новообразованиях [57]. Модель на основе сигнального пути p53/Sirt1 была предложена для изучения регулирующего влияния miR-34 $\alpha$ на Sirt1-опосредованную p53 сигнализацию. Проведенный анализ позволил структурировать возможные варианты механизма ингибирования, оказываемого микроРНК-34 $\alpha$ на p53 через влияние на Sirt1. Авторы считают необходимым адаптировать такую модель для последующего изучения регуляции взаимосвязей Sirt1 и микроРНК для оценки последствий в процессе клеточного старения.

Моделирование динамической регуляторной сети NF-kB и IL-6 опосредованной микроРНК (miR-21 и miR-146) оказалось, что петля отрицательной обратной связи обеспеченная miR-21, моделировала колебания поведения активности NF-kB и IL-6; в то время как отрицательная обратная связь, обеспеченная miR-146, ингибировала активность NF-kB и IL-6 [101]. Авторы утверждают, что благодаря новому регуляторному модулю из двух контуров отрицательной обратной связи, опосредованных микроРНК, можно оптимально настраивать динамику ключевых медиаторов воспаления в старости.

K современным подходам в области системной биологии старения относятся разработки доступных инструментов для стандартизации и автоматизации процесса интеграции модели в формате SBML («system biology Markup Language») язык разметки для представления математических моделей сетей биохимических реакций $[53,87]$. Вычислительные модели способствуют исследователям в интерпретации данных, в лучшем понимании биологических функции и в количественном прогнозировании. Язык разметки системной биологии (SBML) имеет формат файла для представления вычислительных моделей в декларативной форме, которой могут обмениваться различные программные комплексы, и ориентирован на описание различных биологических процессов, включая метаболические пути, клеточный сигналлинг и многое другое. Поддерживая SBML в качестве формата ввода/вывода, различные модельные подходы могут работать с идентичным представлением модели, устраняя возможности для ошибок перевода и обеспечивая общую отправную точку для анализа и моделирования. Показательным примером эффективного использования SBML является работа [65] по динамическому моделированию путей клеточного старения. Авторы использовали предварительно разработанную модель mTOR и абстрагировали её к сетевому формату, сохранив при этом ключевые показатели, необходимые для кодирования особенностей поведения системы, а затем интегрировали их с данными о повреждения ДНК и особенностями стрессовых реакций. 
Следующим этапом было появление CellML - язык разметки на основе XML для описания математических моделей [105]. Он подобен языку разметки SBML системной биологии, но обеспечивает большую область для модульности модели и повторного использования, и не специфичен для описаний биохимии. Хотя теоретически он может описать любую математическую модель, он был первоначально создан с учетом проекта Physiome, и, следовательно, используется в основном для описания моделей, относящихся к области биологии. CellML быстро растет в популярности как портативный формат описания для вычислительных моделей, и группы по всему миру используют CellML для моделирования или разработки программных средств на основе CellML.

В дополнение к рассмотренной программной базе предложены многочисленные дополнительные компоненты. В работе [106], подчеркивается, что воспроизводимость является краеугольным камнем научных исследований. В системной биологии возможность без потерь кодировать и совместно использовать вычислительные модели биологических систем обеспечивается с развитием упомянутых языков разметки системной биологии SBML и CellML. Совсем недавно был выпущен язык разметки описания имитационного эксперимента — SED ML. Этот новый язык разметки расширил область компьютерного моделирования от компьютерного моделирования до экспериментов, выполненных на этих моделях. Вторая версия этого языка обеспечивает включения в рассмотрение «повторяющихся задач», позволяя проводить более сложные эксперименты, такие как сканирование параметров.

SED-ML определяет пять основных классов: модель ссылается на конкретную XML-модель (обычно в SBML или CellML) или на ее модифицированную версию; моделирование определяет конкретный алгоритм; задача связывает алгоритм с моделью, а выходные данные определяют способ передачи результатов задачи пользователю в виде графика или отчета. Текстовые языки позволяют исследователям быстро и легко создавать и изменять экспериментальные протоколы и экспортировать их в общий машиночитаемый формат.

В последнее время для решения проблем, связанных со старением клетки, разработаны, так называемые, гибридные вычислительные подходы. Так, была создана гибридная модель динамической регуляции клеточного цикла [88], использующая лучшие особенности непрерывных дифференциальных уравнений (ОДУ) и дискретных булевых сетей, которые позволили быстро накапливать количественные данные белковых регуляторных сетей в стареющих клетках.

В рамках решения проблемы многомасштабного моделирования представляет интерес разработка [94] сравнительно нового программного обеспечения EPISIM (программный пакет документооборота) для семантической интеграции моделей на основе языка разметки системной биологии SBML в процессе анализа клеточного/тканевого многомасштабного моделирования.

Совсем недавно разработана высокопроизводительная библиотека моделирования («Lib Road Runner») [91] в качестве приложения (на основе Python), которая поддерживает версии для моделей в кодировке SBML. Предполагается, что в будущем будет широко использоваться многомодульное моделирование для многоаспектного изучения возраст-зависимых процессов.

Заключение. С появлением новых инструментов системной биологии и стандартов моделирования динамики клеточного старения, таких как SBML, компьютерные модели стали гораздо более адаптируемыми, а полезный пул моделей существенно вырос.

Однако, несмотря на то, что многие из рассмотренных моделей, которые подвергались обсуждению, сосредоточены на контактных процессах, пока ещё отсутствуют полностью интегрированные модели, которые бы «инкапсулировали» все, или почти все, современные знания о процессе старения [70]. Можно надеяться, что в дальнейшем интеграция моделей позволит устранить многие пробелы в системной биологии [2, 4, 29].

Мы надеемся, что это позволит построить больше интегративных моделей динамики старения в будущем, так как стало понятно, что данный процесс включает сложную систему взаимодействия многих различных механизмов старения.

Выводы. 1. Отсутствие интегрированных трансляционных исследований на пути развития системной медицины и системной биологии является одним из основных факторов, ограничивающих предоставление современных средств в решении проблемы борьбы со старением.

2. Воздействие на митохондрии представляется привлекательной перспективой для достижения улучшения здоровья и продолжительности жизни, 
поскольку омоложение старых митохондрий может оказаться важной терапевтической стратегией для улучшения здоровья пожилых людей.

3. Скорость и простота интеграции современных программных комплексов для моделирования

\section{Литература.}

1. Анисимов В. Н. Молекулярные и физиологические механизмы старения / Анисимов В. Н. - СПб.: Наука, 2003. - 468 с.

2. Артёмов А. В. Старение: различия между смертью клетки и смертью организма с позиции математической модели / Артёмов А. В., Буречковский Э. С. // Український журнал медицини, біології та спорту. - 2016. - 3 (1). - С. 215-220.

3. Войтенко В. П. Математическое моделирование в геронтологии / Войтенко В. П. // Геронтология и гериатрия: ежегодник. Иммунитет и старение. Сб. статей. - К., 1987. - С. 118-130.

4. Воропаева О. Ф. Математическое моделирование функционирования системы белков р53-MDM2 / Воропаева О. Ф., Шокин Ю. Н., Непомнящих Л. М. и соавт. // Бюлл. экспр. биол. и мед. - 2014. № 2. - С. 261-264.

5. Галицкий В. А. Эпигенетическая природа старения / Галицкий В. А. // Цитология. - 2009. - Т. 51, № 2. - С. 388-397.

6. Герасименко Н. Д. Системное воспаление и старение: роль ядерных транскрипционных факторов терапевтической возможности / Герасименко Н. Д., Дегтярь Н. И., Расин М. С. // Проблемы старения и долголетия. - 2016. - Т. 25. - № 4. - С. 554-561.

7. Донцов В. И. Методология сущностного моделирования старения и род моделей, построенных с её помощью / Донцов В. И. // Труды ИСА РАН. - 2006. - Т. 19. - С. 94-116.

8. Крутько В. Н. Системные механизмы и модели старения / Крутько В. Н., Донцов В. И. - M., URSS Press, 2008. - 156 с.

9. Минцер О. П. Методы системной биологии в оценке глобальных перестроек клеточного обмена при хронических заболеваниях обмена веществ / Минцер О. П., Залесский В. Н. // Медична інформатика та інженерія. - 2018. - № 3 (43). - С. 36-43.

10. Новосельцев В. Н. Математическое моделирование в геронтологии - стратегические перспективы / Новосельцев В. Н., Новосельцева Ж. А., Яшина И. // Успехи геронтологии. - 2003. - № 12. - С. 149-165.

11. Халявкин А. В. Подход к моделированию старения с позиции биофизики сложных систем / Халявкин А. В., Крутько В. Н. // Труды ИСА РАН. - 2006. T. 19. - C. 117-155. биологических систем позволяют исследователям изучать большие модели, включая их взаимодействие в многомерных форматах с ансамблями небольших моделей.

12. Aschner Y. Transforming growth factor-beta: master regulator of the respiractory system in health and disease / Aschner Y., Downey G. P. // Am. J. Respir. Cell Mol. Biol. - 2016.

13. Bar C. Telomerase expression confers cardiopratation in the adult mouse heart after acute myocardial infarction / Bar C., Bernardes de Jesus B., Serrano R. et. al. // Nat. commun. - 2014. - № 5. - P. 5863.

14. Barja G. The mitochondrial free radical theory of aging / Barja G. // Prog. Mol. Biol. Transl. Sci. - 2014. № 127. - P. 1-27.

15. Bitean B. Regulation of Drosophila lifespan by JNK signaling / Bitean B., Karpas J., Huangbo D. et. al. // Exp. Gerontol. - 2011. - № 46 (5). - P. 349-354.

16. Bitto A. Biochemical genetic pathways that modulate aging in multiple species / Bitto A., Wang A. M., Behnett C. F. et. al. // Cold Harbor Persp. Med. - 2015. № 5 (11).

17. Brannmark C. Insulin signaling in type 2 diabetes: experimental and modeling analyses reveal mechanisms of insulin resistance in human adipocytes / Brannmark C., Nyman E., Fagerholm S. et. al. // J. Biol. Chem. 2013. - № 288 (14). - P. 9867-9880.

18. Budanov A. V. p53 target genes sestrin 1 and sestrin 2 connect genotoxic stress and mTOR signaling / Budanov A. V., Karin M. // Cell. - 2008. - № 134 (3). - P. 451-460.

19. Carrol B. Autofphagy and ageing: implications for age-related neurodegenerative diseases / Carrol B., Hewitt G., Korolchuk V. I. // Essays Biochem. - 2013. № 55. - P. 119-131.

20. Chen D. SIR 2: a potential target for calorie restriction mimetics / Chen D., Guarente L. // Trends. Mol. Med. - 2007. - № 13 (2). - P. 64-71.

21. Chelliah V. BioModels: ten-year anniversary / Chelliah V., Juty N., Aimera J. et. al. // Nucleic Acids Res. - 2015. - № 43 (Database issue). - P. D 542-548.

22. Cheong J. K. Caseinkinase 1alfpha-dependent feedback loop controls autophagy in RAS-driven cancer / Cheong J. K., Zhang F., Chua P. J. et. al. // J. Clin. Invest. - 2015. - № 125 (4). - P. 1401-1418.

23. Chondrogiani N. Protein damage, repair and proteolysis / Chondrogiani N., Petropulos I., Grimm S. et. al. // Mol. Aspects Med. - 2014. - № 35. - P. 1-71.

24. Cohen A. A. Detection of a novel, integrative aging process suggest complex physiological integration / 
Cohen A. A., Milot E. Li Q. et. al. // PLoS One. - 2015. - № 10 (3). - P. e0116489.

25. Corper A. Chromatin maintenance and dynamics in senescence: a spotlight on SAHF formation and the epigenome of senescent cells / Corper A., Stucki M. // Chromosoma. - 2014. - № 123 (5). - P. 423-436.

26. Costacon $\mathrm{T}$. The prospective association between adiponectin and coronary artery disease among individuales with type I diabetes / Costacon T., Zgibor J. C., Evans R. W. et. al. // Diabetology. - 2005. № 48 (1). - P. 41-48.

27. Crider K. S. Folate and DNA metylation: areview of woleular mechanism and the eridence for folates role / Crider K. S., Yang T. P., Berry R. J. et al. // Adv. Nutr. - 2012. - № 3(1). - P. 21-38.

28. Curtius K. A molecular clock inters heterogenere tissue age accusing patients with Barrott's esghagus / Curtius K., Wong C. J., Hazelton W. B. et al. // Plos. One. 2016. - № 12(5). - P. e1004919.

29. Cvijowic M. Bridging the gaps in system biology / Cvijowic M., Almguist A. J., Hagmar J. et al. // Mol. Genet. Genomics. - 2014. - № 289 (5). - P. 727-734.

30. Dalle Pezze P. Dynamic modeling of pattways to cellular senescence reveals strategies for targeted interveution / Dalle Pezze P., Nelson G., Otten E. G. et al. // PloS. Comput. Biol. - 2014. - № 10(8). - P. e1003728.

31. Dolan D. System modeling of NHEJ reveals the importance of ratex regulation of $\mathrm{Ku} 70 / 80$ in the dynamics of the dna dauge fori / Dolan D., Melson G., Zupanic A. et al. // PLoS Eme. - 2013. - № 8(2). P. e55190.

32. Dolan D. Integrated stohastix model of DNA demage Repair by Non-konofogous End foining and p53/ p21-Mediated Early seneseence sugualliy / Dolan D., Zupanic A., Nelson G. et al. // PloS Compat. Biol. 2015. - № 11 (5). - P. e1004246.

33. Eleyon A. Amino acids and mTORC1: from lysosomcs to disease / Eleyon A., Zoncu R., Sabatini D. H. // Trends Mol. Cell Biol. - 2016.

34. Fang E. F. Nuclear DNA dauage signaling to mitochondria in ageing / Fang E. F., Soheibye-Kuudsen M., Chem F. et. al. // Nat. Rev. Mol. Cell Biol. - 2016.

35. Garcia-Martinez J. M. mTOR complex 2 (mTORC2) controls hydrophobic motif phosphorylation and activation of serum and glucocorticoid-induced protein kinase 1 (SGK 1) / Garcia-Martinez J. M., Alessi D. R. // Biochem J. - 2008. - № 416 (3). - P. 375-385.

36. Gauthier L. D. An integrated mitochondrial ROS production and scavenging model: implications for heart failure / Gauthier L. D., Greenstein J. L., O’Rourke B. et. al. // Biophys J. - 2013. - № 105 (12). - P. 2832-2842.

37. Geva-Zatorsky N. Oscillations and variability in the p53 system / Geva-Zatorsky N., Rosenfeld N., Itzkovitz S. et. al. // Mol. Syst. Biol. - 2006. - № 2. - P. 2006.0033.

38. Goetz R. Klotho co receptors inhibit signaling by paracrine fibroblast growth factor 8 subfamily ligands /
Goetz R., Ohnishi M., Ding X. et. al. // Mol. Cell. Biol. - 2012. - № 32 (10). - P. 1944-1954.

39. Goitre L. The Ras superfamily of small GTP ases: he unlocked secret / Goitre L., Trapani E., Trabalzini L. et. al. // Meth. Mol. Biol. - 2014. - № 1120. - P. 1-18.

40. Govihdarajn D. R. A system analysis of age-related changes in some cardiac aging traits / Govihdarajn D. R., Pencina K. M., Raj D. S. et. al. // Biogerontology. 2014. - № 15 (2). - P. 139-152.

41. Herskovitz A. Z. SIRT1 in neurodevelopment and brain senescence / Herskovitz A. Z., Guarente L. // Neuron. 2014. - № 81 (3). - P. 471-483.

42. Hill S. M. Restricted access: spatial sequestration of damage proteins during stress and aging / Hill S. M., Hauzen S., Nystrom T. // EMBO Rep. - 2017. № 18 (3). - P. 377-391.

43. Hoftman J. M. Effects of age, sex, and genotype on gene-sensitivity metabolomic profiles in the bruit fry, Drosophila melanogaster / Hoftman J. M., Soltow Q. A., Li S. et. al. // Aging Cell. - 2014. - № 13 (4). - P. 596-604.

44. Khan M. H. TAF-4 is required for the life extension of isp-1cek-1 and tpk-1 Mit mutants / Khan M. H., Ligon M., Hussey L. R. et. al. // Aging. - 2013. № 5 (10). - P. 741-758.

45. Kirkwood T. B. Undestanding the odd science of aging / Kirkwood T. B. // Cell. - 2005. - № 120 (4). P. 437-447.

46. Kirkwood T. B. Systems biology of ageing and longevity / Kirkwood T. B. // Philos. Trans.R. So. Lond. B. Biol. Sci. - 2011. - № 366 (1561). - P. 64-70.

47. Kirkwood T. B. L. Somatic mufations and ageing in silico / Kirkwood T. B. L., Proctor C. J. // Mech. Ageing Dev. - 2003. - № 124 (1). - P. 85-92.

48. Kirkwood T. B. L. Why and how are weliving longer? / Kirkwood T. B. L. // Exp. Physiol. - 2017. № 102 (9). - P. 1067-1074.

49. Kitano H. Towards a theory of biological robustness / Kitano H. // Mol. Syst. Biol. - 2007. - № 3. - P. 137.

50. Kowald A. A network theory of aging: the interactions of defective mitochondria, aberrant proteins, free radicals and scavengers in the aging process / Kowald A., Kirkwood T. B. // Mutat. Res. - 1996. № 316 (5-6). - P. 209-236.

51. Kowald A. Accumulation of defective mitochondria through delayed degradation of damaged organelles and its possible role in the ageing of post-mitotic and dividing cells / Kowald A., Kirkwood T. B. // J. Theor. Biol. - 2000. - № 202 (2). - P. 145-160.

52. Kowald A. Mathematical models of mitochondrial aging and dynamics / Kowald A., Klipp E. // Prog. Mol. Biol. Transl. Sci. - 2014. - № 127. - P. 63-92.

53. Krause F. Annotation and merging of SBML models with semantic SBML / Krause F., Ulendorf J., Lubitz T. et. al. // Bioinformatic. - 2010. - № 26 (3). - P. 421-428.

54. Kriete A. Rule-based cell systems model of aging using feedback loop motifs mediated by stress responses / 
Kriete A., Bost W. J., Booker G. // PLoS Comput. Biol. - 2010. - № 6 (6). - P. e1000820.

55. Kriete A. Robustness and aging - a systems level perspective / Kriete A. // Biosystems. - 2013. № 112 (1). - P. 37-48.

56. Labbadia J. The biology of proteostasis in aging and disease / Labbadia J., Morimoto R. I. // Annu Rev. Biochem. - 2015. - № 84. - P. 435-464.

57. Lai X. Modeling miRNA regulation in canor signaling system: miR-34 $\alpha$ regulation of the $\mathrm{p} 53 /$ Sirt1 signaling module / Lai X., Wolkenhauer O., Vera J. // Methods Mol. Biol. - 2012. - № 880. - P. 87-108.

58. Lai X. Understanding microRNA-mediated gene regulatory networks through mathematical modeling / Lai X., Wolkenhauer O., Vera J. // Nucleic Acids Res. - 2016. - № 44 (13). - P. 6019-6035.

59. Lee Y. H. PPARy inhbits inflammatory reaction in oxidative stress induced human diploid fibroblast / Lee Y. H., Lee N. H. Bhattarai G. et al. // Cell. Biochem. Funct. - 2010. - № 28 (6). - P. 490-496.

60. Lipsitz L. A. Loss of «complexity» and aging. Potential applications of fractals and chaos theory to senescence / Lipsitz L. A., Goldberger A. L. // JAMA. - 1992. № 267 (13). - P. 1806-1809.

61. Mao Z. SIRT6 promotes DNA repair under stress by activating / Mao Z., Hine C., Tian X. et. al. // Science. - 2011. - № 332 (6036). - P. 1443-1446.

62. Marin-Garcia J. Mitochondrial DNA repair: a novel therapeutic target for heart failure / Marin-Garcia J. // Hert Fail. Rev. - 2016.

63. Martinez Guimera A. Systems modelling ageing: from single senescent cells to simple multi-cellular models / Martinez Guimera A., Welsh C., Dalle Pezze P. et. al. // Essays Biochem. - 2017. - № 61 (3). - P. 369-377.

64. Maslov A. Y. DNA damage innormally and prematurely aged mice / Maslov A. Y., Ganapathi S., Westerhof M. et. al. // Agine Cell. - 2013. - № 12(3). - P. 467-477.

65. Mc Auley M. T. Modelling the molecular mechanisms of aging / Mc Auley M. T., Martinez Guimere A., Hodson D. et. al. // Biosci. Rep. - 2017. - № 37 (1). - P. BSR 20160177.

66. Mc Govern A. P. A dynamic multi-compartmental model of DNA methylation with demonstrable predictive value in hematological malignance / Mc Govern A. P., Powell B. E., Chevassut T. J. // J. Theor. Biol. - 2012. № 310. - P. 14-20.

67. Medvedev Z. A. An attempt at a rational classification of theories of ageing / Medvedev Z. A. // Biol. Rev. Camb. Philos. Soc. - 1990. - № 65 (3). - P. 375-398.

68. Mendias C. L. Haploin sufficiency of myostatin protects against aging-related declines in musele function and enhances / Mendias C. L., Bakhurin K. I., Gumucio J. P. et. al. // Agine Cell. - 2015. - № 14 (4). - P. 704-706.

69. Miwa S. Mitochondrial turnover in liver is fast in vivo sound is accelerated by dietary restriction: application of a simple dynamic model / Miwa S., Lawiess C., von Zglinicki T. // Aging Cell. - 2008. - № 7 (6). P. 920-923.

70. Mooney K. M. Aging and computational system biology / Mooney K. M., Morgan A. E., Mc Auley M. T. // Wiley Interdiscip. Rev. Syst. Biol. Med. - 2016. № 8 (2). - P. 123-139.

71. Murray P. J. DNA Double-strand break repair: a theoretical framework and its applications / Murray P. J., Cornelissen B., Vallis K. A. et. al. // J. R. Soc. Interfase. - 2016. - № 13 (114). - P. 20150679.

72. Pall M. L. Nrf 2, a master of detoxification and alsoautioxidant, anti-inflammatory and other cytoprotective mechanisms inraised by health promoting factors / Pall M. L., Leine S. // Sheng Li Xue Bao. 2015. - № 67 (1). - P. 1-18.

73. Passos J. F. Feedback between p21 and reactive oxygen production is necessary for cell senescence / Passos J. F., Nelson G., Wang C. et. al. // Mol. Syst. Biol. - 2010. - № 6. - P. 347.

74. Pearson C.A., Zeng C., Simba R. Network class superposition analysis / Pearson C. A., Zeng C., Simba R. // PLoS One. - 2013. - № 8 (4). - P. e59046.

75. Peng L. SIRT1 deacetylates the DNA methyltransferase 1 (DNMT1) protein and alters its activities / Peng L., Yuan Z., Ling H. et. al.// Mol. Cell Biol. - 2011. № 31 (23). - P. 4720-4734.

76. Perkiomaki J. S. Fractal and complexity measures of heart rate / Perkiomaki J. S., Makkikalli T. H., Hyikuri H. V. // Clin. Exp. - 2015. - № 27 (2-3). - P. 149-158.

77. Picca A. Agine and calorie restriction oppositely affect mitochondrial biogenesis through TFAM binding at both origins of mitochondrial DNA replication in rat liver / Picca A., Pesce V., Fracasso F. et. al. // PLoS ONE. 2013. - № 8 (9). - P. e74644.

78. Proctor C. J. Modelling cellular senescence as a result of telomere state / Proctor C. J., Kirkwood T. B. // Aging Cell. - 2003. - № 2 (3). - P. 151-157.

79. Proctor C. J. Modelling the actions of chaperones and their rake in ageing / Proctor C. J., Sotiv C., Boys R. J. et. al. // Mech. Ageing Dev. - 2005. - № 126 (1). P. 119-131.

80. Proctor C. J. Modelling the role of the Hsp 70/Hsp 90 system in the maintenance of protein homeostasis / Proctor C. J., Lorimer I. A. // PLoS One. - 2011.№ 6 (7). - P. e22038.

81. Proctor C. J. A computer simulation approach to assessing therapeutic intervention peints for the prevention of cytokine-induced cartilage breat down / Proctor C. J., Macdonald C., Milner J. M. et. al. // Arthritis Rheumatol. - 2014. - № 66 (4). - P. 979-989.

82. Przybilla J. Understanding epigenetic changes in aging stem cells - a computational model approach / Przybilla J., Rohef T., Loeffeer J. // Aging Cell. - 2014. № 13 (2). - P. 320-328.

83. Junnila R. K. The GH/IGF-1 axis in ageing and longevity / Junnila R. K., List E. O., Berryman D. E. 
et. al. // Nat. Rev. Endocrinol. - 2013. - № 9 (6). P. 366-376.

84. Ramasamy R. The multiple faces of RAGE opportunities for therapeutic intervention in aging and chronic disease / Ramasamy R., Shekhtman A., Schmidt A. M. // Expert Opin. Thez. Tarcets. - 2016. № 20 (4). - P. 431-446.

85. Rattan S. I. Hormesis in aging / Rattan S. I. // Ageing Res. Rev. - 2008. - № 7 (1). - P. 63-78.

86. Rubinsztein D. C. Autophagy and aging / Rubinsztein D. C., Marifio G., Kroemer G. // Cell. - 2011. № 146 (5). - P. 682-695.

87. Schulz M. SBML merge, a system for combining biochemical network models / Schulz M., Uhlendorf J., Klipp E. et. al. // Genome Inform. - 2006. № 17 (1). - P. 62-71.

88. Sighania R. A hibrid model of mammalian cellcycle regulation / Sighania R., Sramkoski R. M., Jacobberger J. W. et. al. // PLoS Comput. Biol. - 2011. - № 7 (2). - P. e1001077.

89. Solovyev I. A. Genetic control of circadian rhythms and aging / Solovyev I. A., Dobrovolskaya E. V., Moskalev A. A. // Russ. J. Genet. - 2016. - № 52 (4). - P. 343-361.

90. Soltow Q. A. A network perspective on metabolism and aging / Soltow Q. A., Jones D. P., Promislow D. E. // Integr. Comp. Biol. - 2010. - № 50 (5). - P. 844-854.

91. Somogyi E. T. Lib Road Runner: a high performance SBML simulation and analysis library / Somogyi E. T., Bouteiller J. M., Glazier J. A. et. al. // Bioinformatics. - 2015. - № 31 (20). - P. 3315-3321.

92. Song R. The system biology of single all aging / Song R., Sarnoski E. A., Acar M. // I Science. - 2018. № 7. - P. 157-169.

93. Sosou P. D. A stochastic model of cell replicative senescence based on telomere shortening oxidative stress, a somatic mutations in nuclear and mitochondrial DNA / Sosou P. D., Kirkwood T. B. L. // J. Theor. Biol. - 2001. - № 213 (4). - P. 573-586.

94. Sutterlin T. Bridging the scale: semantic integration of quantitable SBML in graphical multi-cellular models and simulation with EPISM and COPASI / Sutterlin T., Kolb C., Dickhaus H. et. al. // Bioinformatics. 2013. - № 29 (2). - P. 223-229.

95. Tan Z. Telomere shortening and the population size-dependency of life span of human cell culture / Tan Z. // Exp. Gerontol. - 1999. - № 34 (7). P. 831-842.

96. Tan V. P. Nutrient sensing mTORC1: integration of metabolic and autophagic signals / Tan V. P., Miyamoto S. // J. Mol. Cell Cardiol. - 2016.

97. Tavassoly I. Dynamic modeling of the interaction between autophagy and apoptosis in mammalian cells / Tavassoly I., Parmar J., Shajahan-Hag A. N. et. al. // CPT Pharmacometrics Drug Pharmacol. - 2015. № 4 (4). - P. 263-272.
98. Tilstra J. S. NF-Kb in aging and disease / Tilstra J. S., Clanson C. L., Niedernhofer L. J. et. al. // Agine Dis. 2011. - № 2 (6). - P. 449-465.

99. Tomaru U. Decreased proteasomal activity causes age-related phenotypes and promotes the development of metabolic abnormalities / Tomaru U., Takahashi S., Ishiru A. et. al. // Am. J. Pathol. - 2012. - № 180 (3). - P. 963-972.

100. Van Denrsen J. M. The role of senescent cells in aging / Van Denrsen J. M. // Nature. - 2014. - № 509 (7501). - P. 439-446.

101. Xue X. A modeled dynamic regulatory network of HF-kB and IL-6 mediated by mi RNA / Xue X., Xia W., Wenzhong H. // Biosystems. - 2013. - № 114 (3). - P. 214-218.

102. Wensink M. J. No senescence despite declining selection pressure: Hammilton's result in broader perspective / Wensink M. J., Wrycza T. F., Bandisch A. // J. Theor. Biol. - 2014. - № 347. - P. 176-181.

103. West G. B. Toward a system biology frame work for understanding aging and health span / West G. B., Bergman A. // J. Gerontol. A. Biol. Sci. Med. Sci. - 2009. - № 64 (2). - P. 205-208.

104. Zhang R. The four layers of aging / Zhang R., Chen H. Z., Lu D.-P. // Cell Systems. - 2015. - № 1 (3). P. 180-186.

105. Cuellar A. A. An overview of CellML 1.1, a biological model description language / Cuellar A. A., Lloyd C. M., Nielsen P. F. et. al. // Simulation. - 2003. - № 79(12). - P. 740-747.

106. Kiri C. phraSED-ML: A paraphrased, human-readable adaptation of SED-ML / Kiri C., Smith L. P., Medley J. K., Sauro H. M. // Journal of Bioinformatics and Computational Biology. - 2016. - Vol. 14, № 6. P. 1650035.

107. Theurey P. The Aging Mitochondria / Theurey P., Pizzo P. // Genes. - 2018. - № 9(1). - P. 22.

\section{References.}

1. Anisimov, V. N. (2003). Molekulyarnyie i fiziologicheskie mehanizmyi stareniya [Molecular and physiological mechanisms of aging]. SPb.: Nauka. [In Russian].

2. Artyomov, A.V., Burechkovsky, E. S. (2016). Starenie: razlichiya mezhdu smertyu kletki i smertyu organizma s pozitsii matematicheskoy modeli [Aging: the differences between cell death and death of the organism from the standpoint of a mathematical model]. Ukrainskyi zhurnal medytsyny, biolohii ta sportu (Ukrainian Journal of Medicine, Biology and Sports), 3(1), 215-220. [In Russian].

3. Voitenko, V. P. (1987). Matematicheskoe modelirovanie v gerontologii [Mathematical modeling in gerontology]. Gerontologiya i geriatriya: ezhegodnik. Immunitet i starenie. Sbornik statey (Gerontology and geriatrics: yearbook. Immunity and aging. Digest of articles), Kyiv, 118-130. [In Russian]. 
4. Voropaeva, O. F., Shokin, Yu. N., Nepomnyashchikh, L. M. et al. (2014). Matematicheskoe modelirovanie funktsionirovaniya sistemyi belkov p53-MDM2 [Mathematical modeling of the functioning of the p53 - MDM2 protein system]. Byull. ekspr. biol. i med. (Bull. exp. biol. and honey), 2, 261-264. [In Russian].

5. Galitsky, V. A. (2009). Epigeneticheskaya priroda stareniya [The epigenetic nature of aging]. Tsitologiya (Cytology), 512, 388-397. [In Russian].

6. Gerasimenko, N. D., Degtyar, N. I., Rasin, M. S. (2016). Sistemnoe vospalenie i starenie: rol yadernyih transkriptsionnyih faktorov terapevticheskoy vozmozhnosti [Systemic inflammation and aging: the role of nuclear transcription factors of therapeutic opportunity]. Problemyi stareniya i dolgoletiya (Problems of aging and longevity), 25:4, 554-561. [In Russian].

7. Dontsov, V. I. (2006). Metodologiya suschnostnogo modelirovaniya stareniya i rod modeley, postroennyih s eyo pomoschyu [The methodology of the essential modeling of aging and the genus of models built with its help]. Trudyi ISA RAN (Proceedings of ISA RAS), 19, 94-116. [In Russian].

8. Krutko, V. N., Dontsov, V. I. (2008). Sistemnyie mehanizmyi i modeli stareniya [System mechanisms and models of aging]. Moscow: URSS Press. [In Russian].

9. Mintser, O. P., Zalisky, V. M. (2018). Metodyi sistemnoy biologii $\mathrm{v}$ otsenke globalnyih perestroek kletochnogo obmena pri hronicheskih zabolevaniyah obmena veschestv [Role of the system biology in global modifications of cellular metabolism in chronic metabolic disorders]. Medychna informatyka ta inzheneriia (Medical informatics and engineering), 3(43), 36-43. [In Russian].

10. Novoseltsev, V. N., Novoseltseva, Zh. A., Yashina, I. (2003). Matematicheskoe modelirovanie v gerontologii - strategicheskie perspektivyi [Mathematical modeling in gerontology - strategic perspectives]. Uspehi gerontologii (Successes of gerontology), 12, 149-165. [In Russian].

11. Khalyavkin, A. V., Krutko, V. N. (2006). Podhod k modelirovaniyu stareniya s pozitsii biofiziki slozhnyih system [An approach to modeling aging from the standpoint of biophysics of complex systems]. Trudyi ISA RAN (Proceedings of ISA RAS), 19, 117-155. [In Russian].

12. Aschner, Y., Downey, G. P. (2016). Transforming growth factor-beta: master regulator of the respiractory system in health and disease. Am. J. Respir. Cell Mol. Biol., doi: 10.1165/remb.2015-0391TR.

13. Bar, C., Bernardes de Jesus, B., Serrano, R., et. al. (2014). Telomerase expression confers cardiopratation in the adult mouse heart after acute myocardial infarction. Nat. commun., 5, 5863.

14. Barja, G. (2014). The mitochondrial free radical theory of aging. Prog. Mol. Biol. Transl. Sci., 127, 1-27.
15. Bitean, B., Karpas, J., Huangbo, D., et. al. (2011). Regulation of Drosophila lifespan by JNK signaling. Exp. Gerontol., 46 (5), 349-354.

16. Bitto, A., Wang, A. M., Behnett, C. F., et. al. (2015). Biochemical genetic pathways that modulate aging in multiple species. Cold Harbor Persp. Med.,5 (11). doi: 10.1101/cshpersp.a025114.

17. Brannmark, C., Nyman, E., Fagerholm, S., et. al. (2013). Insulin signaling in type 2 diabetes: experimental and modeling analyses reveal mechanisms of insulin resistance in human adipocytes. J. Biol. Chem., 288 (14), 9867-9880.

18. Budanov, A. V., Karin, M. (2008). p53 target genes sestrin 1 and sestrin 2 connect genotoxic stress and mTOR signaling. Cell, 134 (3), 451-460.

19. Carrol, B., Hewitt, G., Korolchuk, V. I. (2013). Autofphagy and ageing: implications for age-related neurodegenerative diseases. Essays Biochem, 55, 119-131.

20. Chen, D., Guarente, L. (2007). SIR 2: a potential target for calorie restriction mimetics. Trends. Mol. Med., 13 (2), 64-71.

21. Chelliah, V., Juty, N., Aimera, J., et. al. (2015). BioModels: ten-year anniversary. Nucleic Acids Res., 43 (Database issue), D 542-548.

22. Cheong, J. K., Zhang, F., Chua, P. J., et. al. (2015). Caseinkinase 1alfpha-dependent feedback loop controls autophagy in RAS-driven cancer. J. Clin. Invest., 125 (4), 1401-1418.

23. Chondrogiani, N., Petropulos, I., Grimm, S., et. al. (2014). Protein damage, repair and proteolysis. Mol. Aspects Med., 35, 1-71.

24. Cohen, A. A., Milot, E. Li Q., et. al. (2015). Detection of a novel, integrative aging process suggest complex physiological integration. PLoS One, 10(3), e0116489.

25. Corper, A., Stucki, M. (2014). Chromatin maintenance and dynamics in senescence: a spotlight on SAHF formation and the epigenome of senescent cells. Chromosoma, 123 (5), 423-436.

26. Costacon, T., Zgibor, J. C., Evans, R. W., et. al. (2005). The prospective association between adiponectin and coronary artery disease among individuales with type I diabetes. Diabetology, 48(1), 41-48.

27. Crider, K. S., Yang, T. P., Berry, R. J., et al. (2012). Folate and DNA metylation: areview of woleular mechanism and the eridence for folates role. Adv. Nutr., 3(1), 21-38.

28. Curtius, K., Wong, C. J., Hazelton, W. B., et al. (2016). A molecular clock inters heterogenere tissue age accusing patients with Barrott's esghagus. Plos. One, 12(5), e1004919.

29. Cvijowic, M., Almguist, A. J., Hagmar, J., et al. (2014). Bridging the gaps in system biology. Mol. Genet. Genomics, 289(5), 727-734.

30. Dalle Pezze, P., Nelson, G., Otten, E. G., et al. (2014). Dynamic modeling of pattways to cellular senescence reveals strategies for targeted interveution. PloS. 
Comput. Biol., 10(8), e1003728. doi:10.1371/journal. pcbi.1003728.

31. Dolan, D., Melson, G., Zupanic, A., et al. (2013). System modeling of NHEJ reveals the importance of ratex regulation of $\mathrm{Ku} 70 / 80$ in the dynamics of the dna dauge fori. PLoS Eme, 8(2), e55190.

32. Dolan, D., Zupanic, A., Nelson, G., et al. (2015). Integrated stohastix model of DNA demage Repair by Non-konofogous End foining and p53/p21-Mediated Early seneseence sugualliy. PloS Compat. Biol., 11(5), e1004246.

33. Eleyon, A., Zoncu, R., Sabatini, D. H. (2016). Amino acids and mTORC1: from lysosomcs to disease. Trends Mol. Cell Biol. doi:10.1038/nrm. 2016.14.

34. Fang, E. F., Soheibye-Kuudsen, M., Chem, F., et. al. (2016). Nuclear DNA dauage signaling to mitochondria in ageing. Nat. Rev. Mol. Cell Biol. doi:101038/nrm 2016.14.

35. Garcia-Martinez, J. M., Alessi, D. R. (2008). mTOR complex 2 (mTORC2) controls hydrophobic motif phosphorylation and activation of serum and glucocorticoid-induced protein kinase 1 (SGK 1). Biochem J., 416(3), 375-385.

36. Gauthier, L. D., Greenstein, J. L., O’Rourke, B., et. al. (2013). An integrated mitochondrial ROS production and scavenging model: implications for heart failure. Biophys J., 105(12), 2832-2842.

37. Geva-Zatorsky, N., Rosenfeld, N., Itzkovitz, S., et. al. (2006). Oscillations and variability in the p53 system. Mol. Syst. Biol., 2, 0033.

38. Goetz, R., Ohnishi, M., Ding, X., et. al. (2012). Klotho co receptors inhibit signaling by paracrine fibroblast growth factor 8 subfamily ligands. Mol. Cell. Biol., 32(10), 1944-1954.

39. Goitre, L., Trapani, E., Trabalzini, L., et. al. (2014). The Ras superfamily of small GTP ases: he unlocked secret. Meth. Mol. Biol., 1120, 1-18.

40. Govihdarajn, D. R., Pencina, K. M., Raj, D. S., et. al. (2014). A system analysis of age-related changes in some cardiac aging traits. Biogerontology, 15(2), 139-152.

41. Herskovitz, A. Z., Guarente, L. (2014). SIRT1 in neurodevelopment and brain senescence. Neuron, 81(3), 471-483.

42. Hill, S. M., Hauzen, S., Nystrom, T. (2017). Restricted access: spatial sequestration of damage proteins during stress and aging. EMBO Rep., 18(3), 377-391.

43. Hoftman, J. M., Soltow, Q. A., Li, S., et. al. (2014). Effects of age, sex, and genotype on gene-sensitivity metabolomic profiles in the bruit fry, Drosophila melanogaster. Aging Cell, 13(4), 596-604.

44. Khan, M. H., Ligon, M., Hussey, L. R., et. al. (2013). TAF-4 is required for the life extension of isp-1cek-1 and tpk-1 Mit mutants. Aging, 5(10), 741-758.

45. Kirkwood, T. B. (2005). Undestanding the odd science of aging. Cell, 120(4), 437-447.
46. Kirkwood, T. B. (2011). Systems biology of ageing and longevity. Philos. Trans.R. So. Lond. B. Biol. Sci., 366(1561), 64-70.

47. Kirkwood, T. B. L., Proctor, C. J. (2003). Somatic mufations and ageing in silico. Mech. Ageing Dev., 124(1), 85-92.

48. Kirkwood, T. B. L. (2017). Why and how are weliving longer? Exp. Physiol., 102(9), 1067-1074.

49. Kitano, H. (2007). Towards a theory of biological robustness. Mol. Syst. Biol., 3, 137.

50. Kowald, A., Kirkwood, T. B. (1996). A network theory of aging: the interactions of defective mitochondria, aberrant proteins, free radicals and scavengers in the aging process. Mutat. Res., 316(5-6), 209-236.

51. Kowald, A., Kirkwood, T. B. (2000). Accumulation of defective mitochondria through delayed degradation of damaged organelles and its possible role in the ageing of post-mitotic and dividing cells. J. Theor. Biol., 202(2), 145-160.

52. Kowald, A., Klipp, E. (2014). Mathematical models of mitochondrial aging and dynamics. Prog. Mol. Biol. Transl. Sci., 127, 63-92.

53. Krause, F., Ulendorf, J., Lubitz, T., et. al. (2010). Annotation and merging of SBML models with semantic SBML. Bioinformatic, 26(3), 421-428.

54. Kriete, A., Bost, W. J., Booker, G. (2010). Rule-based cell systems model of aging using feedback loop motifs mediated by stress responses. PLoS Comput. Biol., 6(6), e1000820.

55. Kriete, A. (2013). Robustness and aging - a systems level perspective. Biosystems, 112(1), 37-48.

56. Labbadia, J., Morimoto, R. I. (2015). The biology of proteostasis in aging and disease. Annu Rev. Biochem., 84, 435-464.

57. Lai, X., Wolkenhauer, O., Vera, J. (2012). Modeling miRNA regulation in canor signaling system: miR-34 $\alpha$ regulation of the p53/Sirt1 signaling module. Methods Mol. Biol., 880, 87-108.

58. Lai, X., Wolkenhauer, O., Vera, J. (2016). Understanding microRNA-mediated gene regulatory networks through mathematical modelling. Nucleic Acids Res., 44(13), 6019-6035.

59. Lee, Y. H., Lee, N. H., Bhattarai, G., et al. (2010). PPARy inhbits inflammatory reaction in oxidative stress induced human diploid fibroblast. Cell. Biochem. Funct., 28(6), 490-496.

60. Lipsitz, L. A., Goldberger, A. L. (1992). Loss of «complexity» and aging. Potential applications of fractals and chaos theory to senescence. JAMA, 267(13), 1806-1809.

61. Mao, Z., Hine, C., Tian, X., et. al. (2011). SIRT6 promotes DNA repair under stress by activating. Science, 332(6036), 1443-1446.

62. Marin-Garcia, J. (2016). Mitochondrial DNA repair: a novel therapeutic target for heart failure. Hert Fail. Rev. doi:10.1007/S 10741-016-9543-X. 
63. Martinez Guimera, A., Welsh, C., Dalle Pezze. P., et. al. (2017). Systems modelling ageing: from single senescent cells to simple multi-cellular models. Essays Biochem., 61(3), 369-377.

64. Maslov, A. Y., Ganapathi, S., Westerhof, M., et. al. (2013). DNA damage innormally and prematurely aged mice. Agine Cell, 12(3), 467-477.

65. Mc Auley, M. T., Martinez Guimere, A., Hodson, D., et. al. (2017). Modelling the molecular mechanisms of aging. Biosci. Rep., 37 (1), BSR 20160177.

66. Mc Govern, A. P., Powell, B. E., Chevassut, T. J. (2012). A dynamic multi-compartmental model of DNA methylation with demonstrable predictive value in hematological malignance. J. Theor. Biol., 310, 14-20.

67. Medvedev, Z. A. (1990). An attempt at a rational classification of theories of ageing. Biol. Rev. Camb. Philos. Soc., 65(3), 375-398.

68. Mendias, C. L., Bakhurin, K. I., Gumucio, J. P., et. al. (2015). Haploin sufficiency of myostatin protects against aging-related declines in musele function and enhances. Agine Cell, 14(4), 704-706.

69. Miwa, S., Lawiess, C., von Zglinicki, T. (2008). Mitochondrial turnover in liver is fast in vivo sound is accelerated by dictary restriction: application of a simple dynamic model. Aging Cell, 7(6), 920-923.

70. Mooney, K. M., Morgan, A. E., Mc Auley, M. T. (2016). Aging and computational system biology. Wiley Interdiscip. Rev. Syst. Biol. Med., 8(2), 123-139.

71. Murray, P. J., Cornelissen, B., Vallis, K. A., et. al. (2016). DNA Double-strand break repair: a theoretical framework and its aplications. J. R. Soc. Interfase, 13(114), 20150679.

72. Pall, M. L., Leine, S. (2015). Nrf 2, a master of detoxification and alsoautioxidant, anti-inflammatory and other cytoprotective mechanisms inraised by health promoting factors. Sheng Li Xue Bao, 67(1), 1-18.

73. Passos, J. F., Nelson, G., Wang, C., et. al. (2010). Feedback between p21 and reactive oxygen production is necessary for cell senescence. Mol. Syst. Biol., 6, 347.

74. Pearson, C. A., Zeng, C., Simba, R. (2013). Network class superposition analysis. PLoS One, 8(4), e59046.

75. Peng, L., Yuan, Z., Ling, H., et. al. (2011). SIRT1 deacetylates the DNA methyltransferase 1 (DNMT1) protein and alters its activities. Mol. Cell Biol., 31(23), 4720-4734.

76. Perkiomaki, J. S., Makkikalli, T. H., Hyikuri, H. V. (2015). Fractal and complexity measures of heart rate. Clin. Exp., 27(2-3), 149-158.

77. Picca, A., Pesce, V., Fracasso, F., et. al. (2013). Agine and calorie restriction oppositely affect mitochondrial biogenesis through TFAM binding at both origins of mitochondrial DNA replication in rat liver. PLoS ONE, 8(9), e74644.

78. Proctor, C. J., Kirkwood, T. B. (2003). Modelling cellular senescence as a result of telomere state. Aging Cell, 2(3), 151-157.
79. Proctor, C. J., Sotiv, C., Boys, R. J., et. al. (2005). Modelling the actions of chaperones and their rake in ageing. Mech. Ageing Dev., 126(1), 119-131.

80. Proctor, C. J., Lorimer, I. A. (2011). Modelling the role of the Hsp 70/Hsp 90 system in the maintenance of protein homeostasis. PLoS One, 6(7), e22038.

81. Proctor, C. J., Macdonald, C., Milner, J. M., et. al. (2014). A computer simulation approach to assessing therapeutic intervention peints for the prevention of cytokine-induced cartilage breat down. Arthritis Rheumatol., 66(4), 979-989.

82. Przybilla, J., Rohef, T., Loeffeer, J. (2014). Understanding epigenetic changes in aging stem cells - a computational model approach. Aging Cell, 13(2), 320-328.

83. Junnila, R. K., List, E. O., Berryman, D. E., et. al. (2013). The GH/IGF-1 axis in ageing and longevity. Nat. Rev. Endocrinol., 9(6), 366-376.

84. Ramasamy, R., Shekhtman, A., Schmidt, A. M. (2016). The multiple faces of RAGE - opportunities for therapeutic intervention in aging and chronic disease. Expert Opin. Thez. Tarcets., 20(4), 431-446.

85. Rattan, S. I. (2008). Hormesis in aging. Ageing Res. Rev., 7(1), 63-78.

86. Rubinsztein, D. C., Marifio, G., Kroemer, G. (2011). Autophagy and aging. Cell, 146(5), 682-695.

87. Schulz, M., Uhlendorf, J., Klipp, E., et. al. (2006). SBML merge, a system for combining biochemical network models. Genome Inform., 17(1), 62-71.

88. Sighania, R., Sramkoski, R. M., Jacobberger, J. W., et. al. (2011). A hibrid model of mammalian cellcycle regulation. PLoS Comput. Biol., 7(2), e1001077.

89. Solovyev, I. A., Dobrovolskaya, E. V., Moskalev, A. A. (2016). Genetic control of circadian rhythms and aging. Russ. J. Genet., 52(4), 343-361.

90. Soltow, Q. A., Jones, D. P., Promislow, D. E. (2010). A network perspective on metabolism and aging. Integr. Comp. Biol., 50(5), 844-854.

91. Somogyi, E. T., Bouteiller, J. M., Glazier, J. A., et. al. (2015). Lib Road Runner: a high performance SBML simulation and analysis library. Bioinformatics, 31(20), 3315-3321.

92. Song, R., Sarnoski, E. A., Acar, M. (2018). The system biology of single all aging. I Science, 7, 157-169.

93. Sosou, P. D., Kirkwood, T. B. L. (2001). A stochastic model of cell replicative senescence based on telomere shortening oxidative stress, a somatic mutations in nuclear and mitochondrial DNA. J. Theor. Biol., 213(4), 573-586.

94. Sutterlin, T., Kolb, C., Dickhaus, H., et. al. (2013). Bridging the scale: semantic integration of quantitable SBML in graphical multi-cellular models and simulation with EPISM and COPASI. Bioinformatics, 29(2), 223-229.

95. Tan, Z. (1999). Telomere shortening and the population size-dependency of life span of human cell culture. Exp. Gerontol., 34(7), 831-842. 
96. Tan, V. P., Miyamoto, S. (2016). Nutrient sensing mTORC1: integration of metabolic and autophagic signals. J. Mol. Cell Cardiol. doi:10.1016/j. yjmcc.2016.01.005.

97. Tavassoly, I., Parmar, J., Shajahan-Hag, A. N., et. al. (2015). Dynamic modeling of the interaction between autophagy and apoptosis in mammalian cells. CPT Pharmacometrics Drug Pharmacol., 4(4), 263-272.

98. Tilstra, J. S., Clanson, C. L., Niedernhofer, L. J., et. al. (2011). $\mathrm{NF}-\mathrm{Kb}$ in aging and disease. Agine Dis., 2(6), 449-465.

99. Tomaru, U., Takahashi, S., Ishiru, A., et. al. (2012). Decreased proteasomal activity causes age-related phenotypes and promotes the development of metabolic abnormalities. Am. J. Pathol., 180(3), 963-972.

100. Van Denrsen, J. M. (2014). The role of senescent cells in aging. Nature, 509(7501), 439-446.

101. Xue, X., Xia, W., Wenzhong, H. (2013). A modeled dynamic regulatory network of $\mathrm{HF}-\mathrm{kB}$ and IL-6 mediated by mi RNA. Biosystems, 114(3), 214-218.

102. Wensink, M. J., Wrycza, T. F., Bandisch, A. (2014). No senescence despite declining selection pressure:
Hammilton's result in broader perspective. J. Theor. Biol., 347, 176-181.

103. West, G. B., Bergman, A. (2009). Toward a system biology frame work for understanding aging and health span. J. Gerontol. A. Biol. Sci. Med. Sci., 64(2), 205-208.

104. Zhang, R., Chen, H. Z., Lu, D.-P. (2015). The four layers of aging. Cell Systems, 1(3), 180-186.

105. Cuellar, A. A., Lloyd, C. M., Nielsen, P. F., et. al. (2003). An overview of CellML 1.1, a biological model description language. Simulation, 79(12), 740- 747. doi:10.1177/0037549703040939.

106. Kiri, C., Smith, L. P., Medley, J. K., Sauro, H. M. (2016). phraSED-ML: A paraphrased, human-readable adaptation of SED-ML. Journal of Bioinformatics and Computational Biology, 14:06, 1650035. doi:10.1142/ S0219720016500359.

107. Theurey P. (2018). The Aging Mitochondria. Genes, 9(1), 22. doi:10.3390/genes9010022. 